Review

\title{
The Dependence of Opportunistic Behavior from Economic Growth
}

\author{
${ }^{1}$ Natalia Grigoryeva and ${ }^{2}$ Olga Grigoryeva \\ ${ }^{1}$ Institute of Management, Economic and Finance, Kazan (Volga Region) Federal University, Kazan, Russia \\ ${ }^{2}$ Institute of Economics, Management and Law, Kazan, Russia
}

\author{
Article history \\ Received: 16-11-2014 \\ Revised: 04-1-2015 \\ Accepted: 11-5-2015 \\ Corresponding Author: \\ Natalia Grigoryeva \\ Institute of Management, \\ Economic and Finance, Kazan \\ (Volga Region) Federal \\ University, Kazan, Russia \\ Email: Almarus@yandex.ru
}

\begin{abstract}
The study of opportunistic behavior is important because it directly affects the efficiency of economic systems. We conducted qualitative and correlation analysis. The dependence between the manifestations of opportunistic behavior and economic growth was proved. In the article we attempt to identify significant correlation between the rate of economic growth and opportunistic behavior. The study proved the high importance, because it expands our knowledge about the nature of exogenous opportunistic manifestations as an economic phenomenon.
\end{abstract}

Keywords: Opportunistic Behavior, Opportunism, Economic Cycles, Economic Activity, Correlation Analysis, Information Asymmetry

\section{Introduction}

It is believed that the term "opportunism" comes from the Latin "oportunus"-which means "easy", "suitable"; the first field of its applications were political relations. Later this term used by supporters of the K. Marks. However, in Marxism opportunism has acquired a different meaning, as theory and practice in the labor movement, consisting in the refusal of the revolutionary struggle of the proletariat, as capitulation of the working class against the bourgeoisie.

Economists have been interested in understanding patterns of human behavior. Study of opportunistic behavior as a separate object of research began in the late nineteenth century. Veblen (1899) in his study "The Theory of the Leisure Class: An Economic Study of Institutions" tried to determine the nature of opportunism. He believed that the roots of opportunistic behavior lie in the predatory temperament and way of thinking, which in practical application are transformed into actions that lead to fraud, as a maximum-violent seizures.

The interest of researchers from Europe and the US to this topic was observed much earlier than in Russia. The problem of opportunistic behavior was studied in the different areas: Governance of the organization, organizational psychology, works management and so on.

According to the Oliver Williamson, opportunism is a situation when the economic agent provides incomplete or misleading information to counterparties. This behavior leads to information asymmetry, which complicates the behavior of economic relations before the transaction and after it. So, opportunism is an alternative to the assumption of a direct and primitive the following individuals for their interests (Williamson, 1985).

Although the reality situations are consist of a large number of interrelated and interacting elements, it is possible to introduce the assumption that the economic agent decides by choosing from two alternatives: To implement a model of opportunistic behavior or not. But models with a binary choice are not as common in studies.

A number of studies (Alessie et al., 2004; Moon, 2004) shed some lights on the complexity within a binary choice framework. Teraji (2003) adduce an example: even when we talk about economic thought, we often think in terms of two alternative schools or approaches, such as Monetarist versus Keynesian and so on (Fujikawa, 2010; Yucel, 2009).

The asymmetry of information greatly complicates the problem of economic relationship. As a consequence, the stakeholders can deal with much more complex problems in the process of implementing the transaction. Opportunism is the source of behavioral uncertainty, which causes considerable problems in the form of explicit and hidden losses in economic transactions (Bodrov, 2014). Costs of opportunistic behavior are usually attributed to transaction costs, which represent costs of functioning of the market mechanism (Arrow, 1985).

According to Popov (2005), the constant reproduction of opportunistic behavior due to its predominant advantage in comparison with the advantage of good performance. People have different propensity for opportunistic behavior. In a competitive environment people will exhibit different levels of susceptibility to opportunistic behavior depending on the 
social relations between stakeholders and depending on different cultures.

Thus, opportunism in a general sense is a situation when economic agent uses its preferential provisions in order to prejudice the interests of the other stakeholders to the transaction to increase its share of benefits.

Opportunism and opportunistic behavior plays the central role in many sectors of the economic relationship. Opportunism in Russia has a unique national flavor in which social ties are very important (Bodrov, 2014). Opportunistic behavior is studied by modern scholars in the context of organizationaleconomic relations, labor relations, planning and implementation of market transactions, etc. Russian researchers usually use methodological platforms and analytical tools of the institutional approach, the theory of transaction costs when they study opportunistic behavior (Baev and Klimov, 2009).

Despite the theoretical and practical significance, empirical studies of opportunism still are extremely rare. One of the examples that we were found is the work of Lumineau and Quelin (2012). Although the theory of transaction costs considering opportunism as a general concept, the laws of manifestation of opportunistic behavior are still poorly understood. In particular, it is not examined the relationship of the manifestations of opportunistic behavior and economic growth.

Currently there is a growing popularity of the approach, according to which a target value of corporate governance is sustainable development instead of economic growth. Since traditionally the core value guiding corporate governance has basically been of an economic nature, its goal has been to maximize stock value through investor satisfaction. On the other hand, for a dynamic and sustainable firm, the core value is not economic growth but sustainable development (Rodriguez et al., 2002). So, the goal is to create value for shareholders and society through stakeholder satisfaction and engagement and to combine economic growth with social development (Dittmar, 2014).

Under these conditions, when the role of the quality of relationship increases, the study of patterns of opportunistic behavior is especially important. However, because of the economic growth there was already extensive statistics (as opposed to indicators of sustainable development), we have used in our analysis indicator of economic growth.

The stages of the economic cycle affect the behavior of economic agents. In particular, according to the World Health Organization (WHO), the economic crisis has had a significant negative impact on mental health. An economic consequence (in the form of reduced productivity) is estimated at 3-4\% of Gross Domestic Product (GDP) (Publication of the Federation Council Socio-economic consequences of the crisis in Europe № 28 (471)).
Issues associated with the study of patterns of opportunistic behavior are relevant, because it affects to the efficiency of economic and business activity of economic agents as a whole.

\section{Materials and Methods}

With the purpose of studying the regularities of the opportunistic behavior on the pace of economic growth, have been put the following task:

- To study the relationship between the pace of economic growth and the number of economic crimes as facts of opportunistic behavior

- To conduct a quantitative analysis between the values of economic growth and the number of arbitration cases

- To analyze the results obtained for the presence of significant dependencies, reflecting patterns of development and functioning of economic processes

In this study we will try to identify the presence or absence of correlation between the occurrence of opportunistic behavior (mainly in the form of economic crime) and economic growth on the example of the Russian economy.

Based on the foregoing, we believe that all costs related to litigation, should be attributed to the cost of opportunistic behavior. One of the indicators of the costs of opportunistic behavior can be statistics on the number of cases that were considered by Arbitration courts of Russia. We collected and analyzed changes in the following indicators over the period from 2006 to 2013:

- The number of cases which were considered by arbitration courts of subjects (districts) of the Russian Federation

- The amount of the state fee, listed in the Federal budget affairs and claims, considered by arbitration courts of subjects (districts) of the Russian Federation

Information base of statistical data is Unified Interdepartmental Statistical Information System (UISIS) (http://www.fedstat.ru/indicators/start.do) statistical data were processed using the software Microsoft Excel.

\section{Results}

The highest form of opportunism in the economy is intentional committing economic crimes (Lomakin, 2013). However, the relationship between the state of the economy and the number of committed offences are complex.

So, Sergio Herzog, a scientist from the University of Haifa (Israel), have studied the statistics on Palestinians 
working in Israel, comparing the level of unemployment in their environment and the number of crimes (a priori it is assumed that after the loss of work income is drastically reduced). Herzog found no link between poverty and crime. The only exception to this is only one kind of crime-theft of cars (Crime and the economic crisis/the journal Problems of local self-government, 2010. №38/http://www.samoupravlenie.ru/38-07.php).

Jeff Grogger, Professor at the University of California in Los Angeles proves that crime grows there and then, when reduced wages for young low-skilled workers. In this case, criminal hunting is becoming an attractive alternative to honest poverty, because income is a major determinant of individual living standards (Kreishan, 2011).

The economist Simon Hakim, working at the Temple University, also believes that wages and crime are interrelated. However, in his opinion, the state of the economy has on the pace of development of crime only short term and rather limited effect. For example, during crises sharp increase in the number of property crimes, but at the same time, somewhat reduced the number of rapes.

The sociologist Richard Rosenfeld working at the University of Missouri, argues that the relationship between crises and outbreaks of crime there is, however, in his opinion, the crime rate begins to rise approximately one year after the start of the financial crisis and stops about two years after his graduation, because, the crime rate is a reference rate (Crime and the economic crisis/the journal Problems of local selfgovernment, 2010. №38/http://www.samoupravlenie.ru /38-07.php).

The Heritage Foundation study showed that the relationship between economic phenomena and crime exists, but it is not unambiguous. Thus, the U.S. national crime statistics begun in 1934. For all this time only for 16 years the crime rate has decreased. The crime rate grew steadily from 1955 to 1972 , although in this period, the U.S. economy experienced a rapid period of development, weak recession occurred only in the mid 1960-s. In turn, during the great Depression-statistics is only in the period from 1934 to 1938-the criminals showed less activity. In the period from 1957 to 1959 the growth rate of income of the average resident of the United States was $8 \%$ per year in those same years the crime rate has increased by $15 \%$ annually.

In the crisis, a number of economic crimes are growing in Russia and since economic crimes are the highest form of opportunistic behavior in the relationship between economic agents, it can be assumed inversely proportional dependence between the manifestation of opportunistic behavior and economic growth is exist.

One of the factors that affect the crime rate, is considered the state of the economy. The share of Russian shadow economy in the structure of real economic relations was reached at different times and according to different estimates, from 30 to $60 \%$ of GDP (Glynkina, 2003). Even according to the Security Council of the Russian Federation size of the shadow economy in Russia is estimated at $20-25 \%$ of GDP. For comparison, globally, its share is estimated at $5-10 \%$ of GDP. The shadow economy in Russia is about 2-2.5 trillion rubles, which is approximately equal to the revenues of the Federal budget. In the sphere of shadow economy employs about 9 million people (Luneev, 2011). All these figures can be considered like indicators of opportunistic behavior at the macro level and indicator its magnitude in the Russian system of economic relations.

Disputes relating to the protection by economic agents their civil and property rights are considered in the Arbitration courts of the Russian Federation. First of all, among the disputes covered by the arbitration court, it should be noted disputes over violations of the terms of the contract. This can be a situation associated with non-delivery of goods, breach of terms of the performance of obligations under the contract or the provision of services of inadequate quality. The arbitration court considers also cases about the invalidation of agreements, the enforcement of contract, disputes between shareholders of enterprises and etc.

Economic and business crimes are widespread in the Russian judicial practice (Lomakin, 2013). Therefore, they do occur frequently and there are conditions for the perpetration within the existing institutional structure. Shabanova (2007) came to the next result in the study of the behavior of the representatives of Russian business. She has studied types of reactive-adaptive behavior of small and large businesses in response to the establishment by the authorities of undesirable business rules. As a result, more than $60 \%$ of respondents (small and large business) looking for ways around the new rules within the legal field, about $30 \%$ tend to enter into informal agreements with local officials and supervisors. Small business more often tend to extend the shadow realm than large business. $16 \%$ of large business (and only $9 \%$ of small business) trying to challenge the government's actions through business associations, unions and 16\% of large business (and $20 \%$ of small business) would abandon long-term investments in the Russian economy. Only $4 \%$ of respondents do not react, because the violation of legal norms does not entail a serious risk.

So, the majority of firms in the sphere of small and large businesses tend to violate the law, including seeking legal ways to circumvent inconvenient regulations.

In general, opportunistic behavior may manifest as violations of formally prescribed obligations or in violation of informal norms are not fixed in the contract, but intuitively alleged in the transaction. Violation of the codified provisions of the contract entails the costs of protection of interests and, in particular, on trial. These costs represent the costs of opportunistic behavior. 
All proceedings in arbitration courts can be seen as a consequence of opportunistic behavior. Even in those cases when the proceedings are in order to lead the company in unnecessary costs, to force company to spend time and other resources on the trial, although the initial party is not initially expects to win. The possibility of appeals and the subsequent review of the case can be used more than once and to prolong the trial for a long period of time. Also can be called opportunistic those proceedings, which are initialized with the purpose of harming the reputation of the economic agent and not with the purpose of protection of violated rights.

The number of cases which were considered by Arbitration courts of subjects of the Russian Federation for the period from 2006 to 2013 tends to increase, as shown in the Fig. 1.

The amount of the state fee, listed in the Federal budget affairs and claims, considered by Arbitration courts of subjects of the Russian Federation, is also increasing in the period from 2006 to 2013 (Fig. 2). Moreover, the growth rate of the amount of the state fee for the examination of cases by Arbitration courts in Russia exceeds the growth rate of the total number of cases which were examined by the courts.

The growth of paid fees depends on the number of cases considered by the courts and of the amounts of the claims, as according to the Tax code of the Russian Federation the amount of the state fee depends on the number of individual claims and/or the amount of the claim (article 333.21 the size of the state duty for cases in Arbitration courts).

The tendency to increase the number of considered cases annually and the amounts of the fees paid indicates the increase in the number of facts of opportunistic behavior, as well as to increase their scale. The increase in the number of cases entails increased costs of economic agents for legal services, which increases transaction costs in the economy.

The stages of the economic cycle affect to the realization of economic processes and phenomena.
Therefore, manifestations of opportunistic behavior should also vary depending on the state of economic growth.

To search for dependencies of opportunistic behavior from economic growth we have analyzed changes in the index of industrial production, as one of the indicators of economic growth and the number of cases considered by Arbitration courts of the Russian Federation. We found statistical data for time period from 2006 to 2013. This period is sufficiently long to identify functional dependencies or lack of it between the two factors. Different phases of the economic business cycle were marked in the period under review. So, during 2008-2009 a recession was marked by amid the global financial crisis (Fig. 3); 2010-2012 was a period of economic recovery.

Correlation analysis was conducted between the studied indicators (formula 1):

$$
r_{x y}=\frac{\sum(X-\bar{X}) \times(Y-\bar{Y})}{\sqrt{\sum(X-\bar{X})^{2} \times \sum(Y-\bar{Y})^{2}}}
$$

Where:

$\mathrm{r}_{\mathrm{xy}}=$ The linear correlation coefficient

$\mathrm{X}=$ The index of industrial production

$\mathrm{Y}=$ the rate of growth in the number of cases by Arbitration courts of subjects of the Russian Federation

$\bar{X}=$ The average value of the index of industrial production

$\bar{Y}=$ The average value of the index of industrial production

The correlation between the index of industrial production (in \% to the previous year) and the rate of growth in the number of cases by Arbitration courts of subjects of the Russian Federation for the years 20062013 was $-0,7773$. This means that when the economic slowdown, the number of legal claims of economic agents to each other increases. This inverse relationship is statistically significant, because the indicators correlate with each other at $78 \%$.

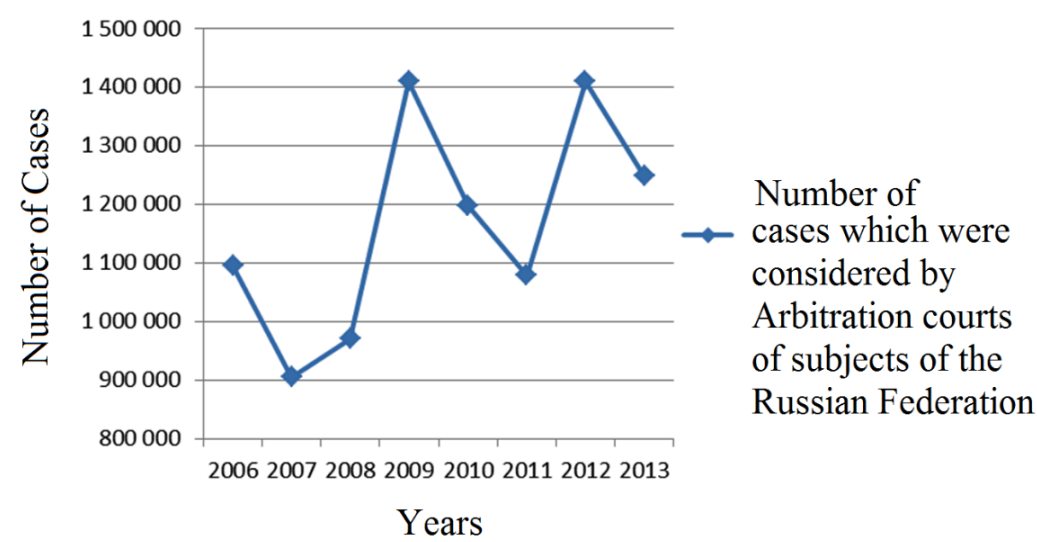

Fig. 1. Number of cases which were considered by Arbitration courts of subjects of the Russian Federation 


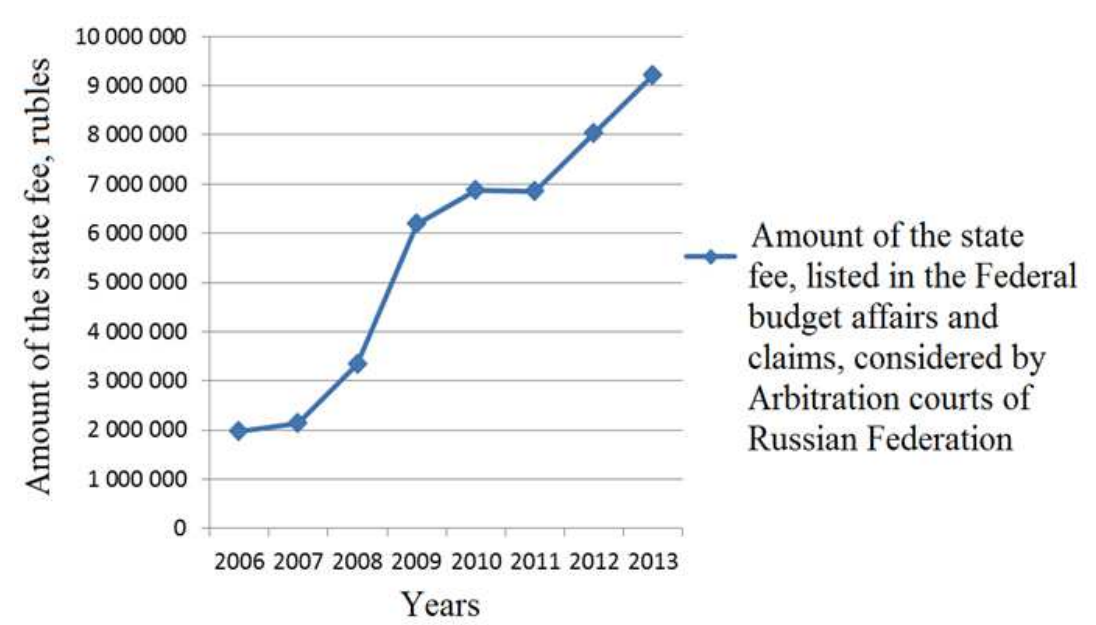

Fig. 2. Amount of the state fee, listed in the Federal budget affairs and claims, considered by Arbitration courts of subjects of the Russian Federation

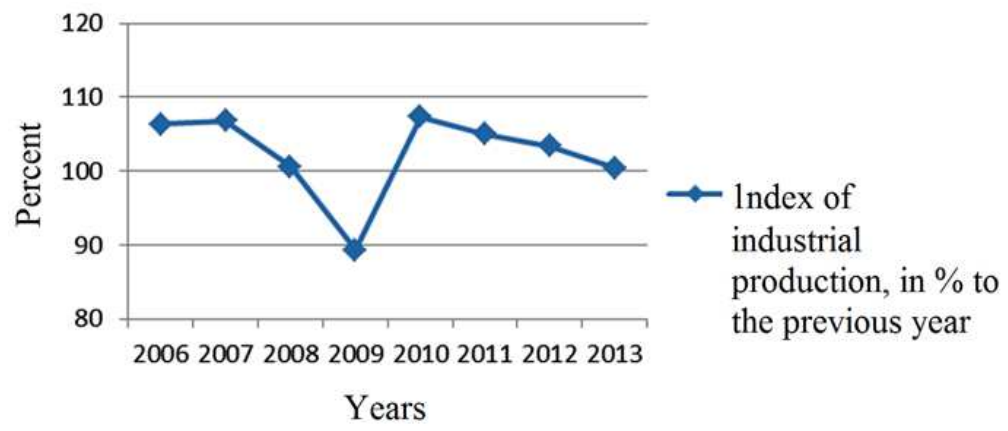

Fig. 3. Index of industrial production, in \% to the previous year, 2006-2013

\section{Discussion}

With an inverse correlation between the rate of economic growth and the rate of change in the number of cases by Arbitration courts of Russia in 2006-2013 years, reflects the dependence of opportunistic behavior from economic growth. We have used indicator of economic growth because there was already extensive statistics (as opposed to indicators of sustainable development; according to the approach of sustainable development, a target value of corporate governance is sustainable development instead of economic growth).

Perhaps in the period of economic slowdown the decrease of the total income in the economy encourages economic agents activate defending of their economic interests. Also, no wonder often the decrease of the total income is stimulant for firms to improve their technical and economic efficiency through innovations (Anastassiou and Dritsaki, 2005) which represent a clear economic advantage but due to the additional investments and possible conflicts (which, for example, relate to personnel reductions as a result of technical innovations). So, the higher is the income, the less the degree of escalation of the conflict is necessary to resolve disputes, because the quality of life influences on economic behavior and economic indicators (Garifova and Kundakchyan, 2014; Safdari et al., 2010). Thus, the costs of opportunistic behavior are growing in the period of economic slowdown.

This can be explained by the fact that in those periods, when the revenue from economic activity are reduced, economic agents use all available tools to protect their civil and property interests, in order to maintain their status-quo. Under favorable conditions, economic development, revenue generation psychologically perceived as sufficient and the part of economic entities disclaims trials, because they evaluate the costs and implicit costs of litigation is higher than the possible result from these proceedings.

An additional argument is the fact that, when the growth rate is higher, there are fewer occasions for opportunistic behavior, because the rate of profit is more and psychologically perceived as sufficient for a comfortable life and business. 


\section{Conclusion}

This study has presented the relationship between the pace of economic growth and the number of economic crimes as facts of opportunistic behavior. After that we hypothesized that all costs related to litigation, should be attributed to the cost of opportunistic behavior and that one of the indicators of the costs of opportunistic behavior can be statistics on the number of cases that were considered by Arbitration courts of Russia.

We have collect statistical data to conduct a quantitative analysis between the values of economic growth and the indicators of the costs of opportunistic behavior (number of Arbitration cases and so on). We found significant correlation between the rate of economic growth and the rate of change in the number of cases by Arbitration courts of Russia in 2006-2013 years, reflects the dependence of opportunistic behavior from economic growth. So, we hypothesized the presence of significant dependencies between the occurrence of opportunistic behavior (mainly in the form of economic crime) and economic growth on the example of the Russian economy.

To sum up, in this study the result of the qualitative and quantitative analysis were revealed a statistically significant dependence of opportunistic behavior from economic growth. That creates the basis for further research in this area and also expands our knowledge about the nature of exogenous opportunistic manifestations as an economic phenomenon.

\section{Acknowledgement}

The researchers thank Prof. Rezeda M. Kundakchyan for the valuable discussions during the development of this study.

\section{Author's Contributions}

Natalia Grigoryeva: Designed the research plan and organized the study. Computer analysis and contributed in the writing of manuscript.

Olga Grigoryeva: Participated in all experiments, coordinated in data-analysis and contributed to the writing of the manuscript.

\section{Ethics}

This article is original and contains unpublished material. The corresponding author confirms that all of other authors have read and approved the manuscript and no ethical issues involved.

\section{References}

Alessie, R., S. Hochguertel and A. van Soest, 2004. Ownership of stocks and mutual funds: A panel data analysis. Rev. Econ. Stat., 86: 783-796.

DOI: $10.1162 / 0034653041811761$
Anastassiou, T. and C. Dritsaki, 2005. Tax Revenues and Economic Growth: An Empirical Investigation for Greece Using Causality Analysis. J. Soc. Sci., 1: 99-104. DOI: 10.3844/jssp.2005.99.104

Arrow, K.J., 1985. The Potentials and Limits of the Market in Resource Allocation. In: Issues in Contemporary Microeconomics and Welfare, Feiwel, G.R. (Ed.), Macmillan, Basingstoke, ISBN-10: 0333354826, pp: 107-124.

Baev, I.A. and B.O. Klimov, 2009. Modelling of opportunistic behavior of managers of industrial enterprises. J. SUSU Series: Econ. Manage., 29: 63-65.

Bodrov, O.G., 2014. Main causes of Staff labor opportunism in organizations. Life Sci. J., 11: 400-408.

Dittmar, M., 2014. Development towards sustainability: How to judge past and proposed policies? Sci. Total Environ., 472: 282-288. DOI: $10.1016 /$ j.scitotenv.2013.11.020

Garifova, L. and R. Kundakchyan, 2014. Quality of life as a factor of socio-ecological and economic assessment. Mediterranean J. Social Sci., 5: 95-100. DOI: $10.5901 / \mathrm{mjss} .2014 . v 5 n 18 p 95$

Glynkina, S.P., 2003. Scientific Approaches to Assess the Extent of the Shadow Economy and its Impact on National Security. 1st Edn., Moscow, pp: 5.

Kreishan, F.M., 2011. Economic growth and unemployment: An empirical analysis. J. Soc. Sci., 7: 228-231. DOI: 10.3844/jssp.2011.228.231

Lomakin, S.V., 2013. Opportunism of the Russian business. Young Scientist, 1: 150-153.

Luneev, V.V., 2011. About the criminalization of economic crimes entrepreneurs. Institute of State and Law of Russian Academy of Sciences.

Lumineau, F. and B.V. Quelin, 2012. An empirical investigation of interorganizational opportunism and contracting mechanisms. Strategic Organ., 10: 55-84. DOI: $10.1177 / 1476127011434798$

Moon, H.R., 2004. Maximum score estimation of a nonstationary binary choice model. J. Econ., 122: 385-403. DOI: 10.1016/j.jeconom.2003.10.027

Popov, E.V., 2005. Institutions of Mikro-Economics. 1st Edn., Publishing House "Economy", Moscow, pp: 125.

Rodriguez, M.A., J.E. Ricart and P. Sanchez, 2002. Sustainable development and the sustainability of competitive advantage: A dynamic and sustainable view of the firm. Creativity Innov. Manage., 11: 135-146. DOI: 10.1111/1467-8691.00246

Safdari, M., M. Shahiki and Z. Sheidaee, 2010. How Does Human Capital Affect on Growth in Different Economies? J. Soc. Sci., 6: 416-423. DOI: $10.3844 /$ jssp.2010.416.423

Shabanova, M.A., 2007. Successful economic actors: Adaptation and protest behavior in wrongful field. Sociol. Res., 10: 39-51. 
Teraji, S., 2003. Herd behavior and the quality of opinions. J. Sociol. Econ., 32: 661-673. DOI: $10.1016 /$ j.socec.2003.10.004

Yucel, F., 2009. Causal relationships between financial development, trade openness and economic growth: The case of turkey. J. Soc. Sci., 5: 33-42.

DOI: $10.3844 /$ jssp.2009.33.42
Veblen, T., 1899. The theory of the leisure class: An economic study of institutions.

Williamson, O.E., 1985. The Economic Intstitutions of Capitalism. 1st Edn., Simon and Schuster, ISBN-10: 068486374X, pp: 468. 